\title{
Impact of Economic Growth, Energy Use and Population Growth on Carbon Emissions in Sub-Sahara Africa
}

\author{
Max William Ssali ${ }^{1}$, Jianguo Du ${ }^{1}$, Duncan Omenda Hongo ${ }^{2}$ and Isaac Adjei Mensah ${ }^{3}$ \\ 1. School of Management, Jiangsu University, Zhenjiang 212013, PR China \\ 2. School of Statistics, Jiangsu University, Zhenjiang 212013, PR China \\ 3. Faculty of Science, Jiangsu University, Zhenjiang 212013, P R of China
}

\begin{abstract}
The study examines the impact of economic growth, energy use and population growth on carbon emissions in sub Saharan Africa: Kenya, Nigeria, Botswana, Benin, Togo and Mauritius for the period of 1990-2014. The study employed unit root test, co-integration test, VECM (Vector Error Correction Model) and FMOLS (Fully Modified Ordinary Least-Square) as methodologies to model the causality and linear relationships amongst the variables. The VECM was used to identify the long-run causality and asymptotic convergence among the variables. The results reveal that an increase in energy use and population growth by $1 \%$ would cause an increase in $\mathrm{CO}_{2}$ (Carbon Dioxide) concentration by $0.08 \%$ and $0.22 \%$ correspondingly, whereas in the long-run $1 \%$ increase of energy use increases economic output by $0.09 \%$. As the economy grows without contributing to carbon emissions, governments should invest more in renewable energy. Governments should also come up with policies to regulate population growth and fossil energy use.
\end{abstract}

Key word: Carbon emissions, economic growth, energy use, population growth.

\section{Introduction}

The impact of economic growth and energy use on carbon emissions is evolving into a serious topic among researchers [1-3]. Factors like increase in population, energy use, economic growth, demand for goods and services have contributed to the increase of carbon-dioxide emission in Sub Saharan Africa [4-7], and reiterate that energy use for economic growth, has led to massive production of carbon emissions which have led to climate change and increase in respiratory diseases and asthma. According to researchers [2, 5, 8-10], carbon emissions is on increase in Sub-Saharan Africa. There is an increase in the utilization of fossil energies in Sub-Saharan Africa that has advanced poor economic growth; despite renewable sources of energies are used their wastes are capable of polluting the environment; and endangering millions of

Corresponding authors: Max William Ssali, Ph.D., research fields: management science and engineering; Duncan Omenda Hongo, Master, research field: macroeconomics. biological species [11].

More researchers [7, 12] reported that carbon emissions have affected health globally. According to Ref. [13], carbon emissions have led to a total of $7,000,000$ deaths every year globally. That is, it has contributed to $24 \%$ of deaths caused by heart diseases as a result of air pollution, $25 \%$ caused by stroke as a result of $\mathrm{CO}_{2}$ (Carbon Dioxide), 43\% deaths among adults caused by chronic obstructive pulmonary disease and finally $29 \%$ as result of lung cancer engineered by carbon emissions. Ref. [11] revealed that as much as energy fabrication is vital for industrialization in emerging economies, and has manifested a lot of challenges like air pollution. Lelieveld and Evans [14] also revealed that air contamination is related with numerous wellbeing impacts, including endless obstructive aspiratory ailments connected to upgraded ozone $\left(\mathrm{O}_{3}\right)$ : that $\mathrm{PM}_{2.5}$ is responsible for intense lower respiratory sickness, cerebrovascular malady, ischemic coronary illness, obstructive aspiratory ailment and lung malignancy. 
Human activities have contributed much to carbon emissions in Africa threatening the future of the biodiversity [15]. Ref. [16] stated that the Climate Agreement in France-Paris by UNFCCC (United Nations Framework Convention about Climate Change) (COP21), on 30th Nov. to 11th Dec., 2015 obligated nations to reduce the global rising temperature way below at least $2{ }^{\circ} \mathrm{C}$ to set a more optimistic objective to restrict global warming to $1.5^{\circ} \mathrm{C}$.

Economic growth plays a critical role in the improvement of the national output and improving living standards, reducing unemployment and reduction of nation debts $[17,18]$. The issue of economic growth has been greatly emphasized by many researchers [19-22] to be the result of carbon emissions. In the past years, there has been an intensification of environmental pollution in the Sub-Saharan Africa. Ref. [23] used FMOLS (Fully Modified Ordinary Lest-Square) in their study to find the effect of the variables they used. Their findings revealed that growth in GDP, urbanization, and financial expansion increases $\mathrm{CO}_{2}$ emissions in the long run. Refs. [24, 25] reiterated that there is a huge usage of fossil fuel for energy which has contributed to environmental degradation and diseases as a result of using firewood in Sub-Saharan Africa. Ref. [26] investigated environmental factors, which affect health signs by applying FMOLS methodology. Their findings revealed that carbon emissions affect the health of Africa especially Sub-Saharan-Africa.

Therefore, this study seeks to contribute to the existing literature by elucidation of the impact of economic growth and energy use on environmental pollution in Sub-Saharan Africa. The study seeks to find answers to questions like: (i) Does economic growth impact carbon emissions? (ii) To what extent does energy use influence carbon emissions? (iii) Do economic growth, energy use and population have any impact on carbon emissions in Sub-Saharan African nations? For these questions to be answered, it is necessary to find out the causal impact of economic growth, energy use and population growth on carbon emissions in Sub-Saharan Africa. The causal impact of economic growth and energy use and population on carbon emissions when clearly understood will in a great deal help in the endorsement of actions and employment of the anticipated improvements to alleviate environmental pollution as well as promote green economic activities. This study, therefore, seeks to reveal the distinctive individual solutions to challenge carbon emissions globally.

The rest of the study structured as follows: The second section reviews the related literature, the third section does the data and method, presentation of econometric approach and the framework structure, the fourth section entails the result and discussion. The empirical results presented in the fifth section while section six concludes.

\section{Material and Methods}

\subsection{Materials}

Numerous number of researchers [1-3], have examined the impact of economic growth, energy use and population on carbon emissions in Sub-Saharan Africa. The relationship between economic growth, energy use, population and environmental pollution has been a topic of concern for several years [27, 28]. Different methods and strategies have been applied by researchers to examine the relationship between economic growth and energy use and secondly, to investigate the relationship between economic growth and carbon emissions to validate the legitimacy of the EKC hypothesis.

Most investigators [29] revealed diverse type of linkage between environmental emanations and economic development utilizing factors like $\mathrm{CO}_{2}$ discharge nitrous oxide and sulfur dioxide to quantify air contamination and GDP to gauge economic growth.

\subsubsection{Energy Use and Carbon Emissions}

The influence of energy use on carbon emissions has been a debatable issue. Several studies have 
examined the causal relationship between energy use and $\mathrm{CO}_{2}$ emissions. A number of scholars $[30,31]$ revealed that energy use positively influences carbon emission. Using different methods and strategies, numerous researchers [32-37] have examined the nexus between economic growth and energy use. Most of them [36, 38, 39] have revealed the presence of a long-run co-integration between economic growth and energy use. Refs. [40, 41] offered a comprehensive examination about energy enhancement and in addition energy improvement and of late. They additionally attempted to discover the derivations of the vitality development and causality cooperation in the system of the movement discourse, where the vitality and growth association has a vital impact. Ref. [42] examined the transitory (short-run) as well as at everlasting (long-run) causal interconnection amongst energy use and economic growth in 119 countries. Their results indicated that there is a need for public policy for carbon mitigation.

\subsubsection{Economic Growth and Carbon Emissions}

Ref. [21] revealed that economic growth has continuously turned into a noteworthy worldwide concern, and that it ought to likewise be noticed that enthusiasm for this field has been further heightened because of the somewhat complicated character of this specific nexus, both from a hypothetical and an observational point of view. The impact of economic growth on carbon emissions has been a debatable matter for quite a long period. A large number of studies have investigated the impact of economic growth, energy utilization and urbanization on carbon emissions and the results revealed that economic growth has been more instrumental and detrimental to environmental pollution mainly at the primary level. Again, on the other hand, Environmental-Kuznet-Curve hypothesis assumes that at the advanced stage, the negative result of the eco-system is converse due to income increase, which offers adequate solutions to handle the challenges of environmental pollution. Based on the literature, some scholars [43, 44] considered energy utilization and economic growth in the formation of their models to examine their impact on $\mathrm{CO}_{2}$ emissions. Their findings revealed that these two variables have positive impacts on $\mathrm{CO}_{2}$ emissions.

According to Ref. [45], several studies advocated that gigantic economic growth contribute to the increase in $\mathrm{CO}_{2}$ emissions. Other studies by Refs. [46-48] show that economic growth has played a great role in carbon emissions.

According to Ref. [49], they revealed that $\mathrm{CO}_{2}$ outflow has expanded throughout the years globally because of globalization and quick monetary exercises. They added that the expansion in human exercises, for instance, production, transport, power age and utilization of merchandise and enterprises add to the economic growth, which has contributed to ecological contamination. That is, increment in economic development, which includes exercises like an expansion in the presence of foreign investors in the African Countries. Increment in agro exercises and misallocation of industries have contributed to a high usage of nonrenewable energy. Ref. [50] examined the relationship between energy usage and economic growth using panel estimation systems in Sub-Saharan African countries on a time range of 1980 to 2011. Their results found a long-run connection between the key variables, which implies that there is an increase in the consumption of energy contributing to environmental pollution. They were able to identify the direction of causal nexus as well as unidirectional causality.

\subsubsection{Population and Carbon Emission}

Most empirical investigations suggest that population growth was once considered to be one of the environmental factors which have contributed to carbon emissions and as well as economic growth $[51,52]$.

Ref. [53] investigated the association between urbanization and carbon emissions in the case of developing countries of which Sub-Saharan Africa is 
part. They found a negative association between $\mathrm{CO}_{2}$ emissions and urbanization. Other studies revealed a positive relationship between population increase and carbon emissions [54]. Ref. [55] revealed that there is a positive impact of urban growth on carbon emissions but on the other hand, it is insignificant once combined $\mathrm{CO}_{2}$ emissions are utilized as dependent variables. An examination was done by Ref. [56], considering 99 nations to find out the effect of population upon carbon emissions. The outcome of this examination proved that the effect of population upon carbon emissions is positive for stable economies but more significantly positive upon progressing nations.

\subsection{Methodology}

It is profound that the usage of panel data originates with challenges and successes, even when panel replicas may grieve from the concerns of complex gathering or grading structure of the data. Nevertheless, the usage of panel data is capable of handling the complexities of variables under consideration. It is also capable of dealing with human way of doing things (behaviors) than cross section or single-time-series data. Panel data comprise cross-sectional time series observations for numerous individual countries, which is vital when scrutinizing the heterogeneity features and it caters for omitted variables. According to the problems recognized, authors investigated to find out if or not the data utilized in this research grieve from the earlier mentioned issues so that the appropriate methodologies are used.

Authors used panel data to examine the impact of economic growth, energy use and population on environmental pollution of five Sub-Saharan African countries considered for this study. These countries are Kenya, Nigeria, Botswana, Benin and Mauritius. Authors did not consider all Sub-Saharan African countries because some of them did not have complete data. The data utilized in this study are extracted from the World Bank development Indicators (https://data.worldbank. org/indicator) from 1990 to 2014 as indicated in Table 1. The study used econometric models to investigate the causal impact of economic growth, energy use and population on environmental pollution of the selected countries from Sub-Saharan Africa, with panel data of 1990-2014. The abbreviations of the variables and their source are shown in Table 1. The target variable is $\mathrm{CO}_{2}$ emission used as a proxy measure of environmental pollution. It is measured as $\mathrm{CO}_{2}$ emission metric ton per capita, whereas the independent variables are economic growth measured by GDP per capita, energy use is measured by energy use per capita and population growth measured by population growth annual $\%$.

All variables are taken at their natural logarithms because it is a usual trend in analyzed econometrics. The reason for doing this is to change the variables from their exponential growth designs into series that would be in the position to follow a linear trend, to achieve the pliability, which can reveal the interrelationship effects of the independent variables upon the dependent variable for this case carbon emissions.

The study is interested in modeling the causality and linear relationships amongst the variables by modelling a panel VECM (Vector Error Correction Model), an FMOLS and unrestricted VAR (Vector Autoregressive) models. The VECM is used to identify the long-run causality and asymptotic convergence among the

Table 1 Definition of variable.

\begin{tabular}{llll}
\hline Abbreviation & Variable name in full & Component & Source \\
\hline $\mathrm{CO}_{2}$ & $\mathrm{CO}_{2}$ emission metric ton per capita & Environmental Pollution & World Development Indicator (2017) \\
$\mathrm{GDP}$ & Gross Domestic Product per capita & Economic Growth & World Development Indicator (2017) \\
$\mathrm{Eu}$ & Energy use per capita & Energy use & World Development Indicator (2017) \\
$\mathrm{Pg}$ & Population growth annual \% & Population Growth & World Development Indicator (2017) \\
\hline
\end{tabular}


Table 2 Descriptive statistics.

\begin{tabular}{llllll}
\hline Variable & Mean & Max & Min & Standard. dev. & Jarque-Bera \\
\hline $\mathrm{CO}_{2}$ & 8.549105 & 11.55875 & 6.061548 & 1.572734 & $11.50617^{*}$ \\
$\mathrm{Eu}$ & 6.404786 & 7.133041 & 5.665625 & 0.398731 & $11.66429^{*}$ \\
$\mathrm{GDP}$ & 7.54035 & 9.122998 & 6.358778 & 0.849035 & $14.08196^{*}$ \\
$\mathrm{Pg}$ & 0.679109 & 1.325725 & -1.8317 & 0.645264 & $180.7049^{*}$ \\
\hline
\end{tabular}

*significance at $1 \%$.

variables. The VAR is crucial in modelling the granger causality amongst these variables. The FMOLS on the other hand hints out whether a significant interdependence exists amongst output, energy use, population and environmental pollution. The study will also analyze their magnitude and direction of causality beyond the current study period courtesy of VD (Variance Decomposition) and IRF (Impulse Response Function) see [57-60].

\subsection{Descriptive Statistics}

The randomness, mean, Median, Maximum, Minimum, Standard Deviation, Skewness, Kurtosis and Jarque-Bera were carried out over the variables as seen in the descriptive analysis in Table 2.

The analysis revealed that $\mathrm{CO}_{2}$ has the highest mean of 8.55, which singles it out as the life-threatening variable and population growth with the lowest mean of 0.67 in Sub-Saharan African countries under examination. This means that even when the economy grows, there is no way it can affect carbon emissions negatively. Although the Jargue-Bera results are statistically significant the variable may be normally distributed in the country specific series but abnormally spread across the panel. The maximum value indicates that carbon emission is the highest with 11.6, the lowest being population growth with 1.33. The minimum highest value is carbon emissions with 6.36 and the lowest is population growth with -1.83 . The standard deviation is highest with carbon emissions with 1.57 as opposed to other variables. Energy use is the lowest standard deviation value with 0.39. Among all the variables according to the descriptive analysis, under Jarque-Bera, population growth has the highest value of 180.70. This means that the population growth among the independent variables is most likely to contribute a lot to the emanation of $\mathrm{CO}_{2}$ in the selected countries. There is a positive relationship between population growth and carbon emissions.

\subsection{Co-integration and Econometric Equation Building}

In this paper, authors explicate authors' econometric method of panel co-integration test. The tests were executed with the deterministic trend specification at individual slope as evident from the graphical time plots for the individual series. Suppose the series turn out I (1) process as envisioned in authors' study, intuitively it would suggest being co-integrated. To model such co-integration equation and later FMOLS, authors start by presuming that the variables perpetrate a single co-integration vector, which takes the Eq. (1):

$$
p_{i t}=\tau_{i}+\partial_{i} t+\eta q_{i t}+\varepsilon_{i t}, \quad i=1 \ldots 4 \quad t=1 \ldots T
$$

where $p$ and $q$ constitute a vector of I(1) variables for the dependent and independent variables respectively, $\tau$ is the individual trend due to heterogeneous structural economies, varied industrial and population growth characteristics and developments, sectorial variations etc.. $\partial_{i}$ denotes homogenous time drift across the countries which is allowed to converge to equilibrium. $\eta_{i}$ is an $N \times 1$ co-efficient matrix due to $q$, $\varepsilon_{i t}$ refers to a $1 \times N$ error term matrix and an iid processes with $N\left(0, \delta^{2}\right)$. Authors run Eq. (1) under $H_{0} \sim \varepsilon_{i t}$ is I (1) (for no long-run convergence) versus the null for convergence.

Secondly, Hansen [61], Phillips and Hansen [62] suggest that by the application of FMOLS there exists 
co-integration process, possessing unidirectional lengthy covariance matrix in residuals as illustration in Eq. (2).

$$
g_{i t}=q_{i t}^{\prime} \eta_{i}+D_{1 i t}^{\prime} \gamma_{1}+\varepsilon_{1 i t}
$$

where $g_{i t}$ represents $k \times 1$ vector matrices for endogenous variables. $D_{1 i t}^{\prime}$ denotes the deterministic trend regressor is also included in the co-integration term. $q_{i t}$ is associated with

$$
q_{i t}^{\prime}=\tau_{i t}^{\prime} D_{1 i t}+\varepsilon_{2 i t}
$$

After estimating Eq. (2), authors obtain $\hat{\varepsilon}_{2 i t}$ which is employed to model the FMOLS Eq. (4). $g^{*}$ is an estimate of $g$

$$
g_{i t}^{*}=g_{i t}-\hat{\varpi}_{i t} \text { 次栥 } \varepsilon_{2 i t},
$$

where $\hat{\psi}$ is the long-run matrix of covariance constructed across the panel section. $\hat{\vec{w}}_{i t}$ is a scalar estimator.

Furthermore, authors are interested in exploring the direction of causality among the variables. Intuitively, authors modelled unrestricted panel VAR model that aided in constructing the Wald's tests in order to validate the causality significance. Herein, $g_{i t}$ represents vector of the variables in their first difference states in which they are stationery. This test is crucial because of its applicability to investigate the granger causality amongst the variable and because of its improved certainty precision [63].

$$
g_{i t}=R_{o}(t)+R(\ell) g_{t-1}+\varepsilon_{1 i t},
$$

where $R(1)$ represents a polynomial in the lag operator with reference to the variables, $R_{0}(\mathrm{~T})$ is the deterministic trend and $g_{t-1}$ is the one time lag of $g_{i t}$. Authors run Eq. (5) proceeded by the Wald test.

\section{Empirical Results and Discussion}

The study employed a complete conceptual framework including a unit root test, panel co-integration test; panel VECM, FMOLS and unrestricted VAR models with the intention to model the causality and linear relationships amongst the variables. The VECM was used to identify the long-run causality and asymptotic convergence among the variables. Authors utilized LPSW (Lm, Pesaran \& Shin West) and LLC (Levin, Lin \& Chun) to estimate unit root tests on all variables at both intercepts as depicted by their graphical plots. Table 3 summarizes these results.

From the table, all the series (except for population growth (Pg) by LLC) are non-stationary at level with insignificant test statistics at $1 \%$ C.V. By LLC, PG seems to be stable but unstable by LPSW with $t$-statistics of [-2.498] and [-1.259] respectively. After first difference, the series became stationary with significant $t$-statistics by both LLC and LPSW methodologies. As a result, $\mathrm{CO}_{2}, \mathrm{Eu}, \mathrm{GDP}$ and $\mathrm{Pg}$ series were all I (1) process.

When authors executed panel co-integration test of Ref. [64] and on economic growth, energy use, population growth and environmental pollution at lag 1 , which was the most optimal lag, authors resulted to the findings in Table 4. Johansen panel co-integration test was executed at the deterministic trend specification and individual slope as evident from the graphical time plots. Authors embraced the Kao (Engle Granger) test because the series seemed to

Table 3 Unit root test.

\begin{tabular}{lllll}
\hline \multirow{2}{*}{ Variables } & \multicolumn{2}{c}{ level } & \multicolumn{2}{c}{$\Delta$} \\
\cline { 2 - 5 } & LLC & LPSW & LLC & LPSW \\
\hline $\mathrm{CO}_{2}$ & $-1.306(0.096)$ & $1.089(0.862)$ & $-8.416(0.000)^{* * *}$ & $-7.811(0.000)^{* * *}$ \\
$\mathrm{GDP}$ & $1.065(0.857)$ & $4.543(1.000)$ & $-7.321(0.000)^{* * *}$ & $-7.091(0.000)^{* * *}$ \\
$\mathrm{Eu}$ & $0.329(0.629)$ & $4.543(1.000)$ & $-8.499(0.000)^{* * *}$ & $-8.477(0.000)^{* * *}$ \\
$\mathrm{Pg}$ & $-2.498(0.006)^{* * *}$ & $-1.260(0.10)$ & $6.446(0.000)^{* * *}$ & $-6.446(0.000)^{* * *}$ \\
\hline
\end{tabular}

*** Significance at $5 \%, \mathrm{H}_{0}$ : non-stationary, $\Delta$-first difference and numbers in round brackets represent the $\mathrm{t}$ statistics. All four variables were tested at their logged state. The test equation was done at intercept using logged variables. 
Table 4 Panel cointegration.

\begin{tabular}{llll}
\hline \multirow{2}{*}{ Johansen } & No. of cointegration equations & Trace statistics & Max-Eigen statistics \\
\cline { 2 - 4 } & None & $94.6(0.00)^{* * *}$ & $79.5(0.00)^{* * *}$ \\
& At most 1 & $26.5(0.00)^{* * *}$ & $20.9(0.02)^{* *}$ \\
& At most 2 & $13.6(0.19)$ & $8.52(0.58)$ \\
Kao & At most 3 & $18.24(0.05)$ & $18.24(0.05)$ \\
\hline
\end{tabular}

$* * *$ and $* *$ denote rejection at $1 \%$, and $5 \%$ critical value. Lag interval 1,$1 ; \mathrm{H}_{0}$ : no cointegration.

Table 5 FMOLS output.

\begin{tabular}{lllll}
\hline $\begin{array}{l}\text { Models' } \\
\text { Dependent variable }\end{array}$ & $\mathrm{CO}_{2}$ & $\mathrm{GDP}$ & $\mathrm{Eu}$ & $\mathrm{Pg}$ \\
\hline $\mathrm{CO}_{2}$ & - & $0.127(0.519)$ & $0.075(0.000)^{* * *}$ & $0.218(0.037)^{* *}$ \\
$\mathrm{GDP}$ & $0.556(0.066)^{*}$ & - & $0.088(0.000)^{* * *}$ & $-0.101(0.667)$ \\
$\mathrm{Eu}$ & $2.817(0.000)^{* * *}$ & $1.101(0.001)^{* * *}$ & - & $-2.955(0.000)^{* * *}$ \\
$\mathrm{Pg}$ & $0.359(0.044)^{* *}$ & $-0.0559(0.052)^{*}$ & $-0.132(0.000)^{* * *}$ & - \\
\hline$* * *, * *$ and $*$ denote rejection at $0.1 \%, 5 \%$ and $10 \%$ C.V Kernel: Bartlett, Bandwidth: Newey-West fixed,
\end{tabular}
Lag used is 1, 1. Model types used: log-log.

Table 6 VECM model.

\begin{tabular}{lll}
\hline $\begin{array}{l}\text { Models' } \\
\text { Dependent variable }\end{array}$ & $\begin{array}{l}\text { Short-run coefficient } \\
\text { Chi-square statistics }\end{array}$ & $E C T_{t-1}$ \\
\hline $\mathrm{CO}_{2}$ & $0.669(0.955)$ & $0.0019(0.348)$ \\
$\mathrm{GDP}$ & $2.627(0.622)$ & $-0.0015(0.009)^{* * *}$ \\
$\mathrm{Eu}$ & $3.581(0.466)$ & $-0.0017(0.009)^{* * *}$ \\
$\mathrm{Pg}$ & $4.524(0.339)$ & $0.0031(0.087)^{*}$ \\
\hline$* * * * *$ and * denote rejection at $1 \%, 5 \%$ and $10 \%$. Optimal lag is 1 to 1 by both Akaike and Schwarz Information Criterion. Model \\
types used: log-log.
\end{tabular}
types used: log-log.

postulate an individual slope. Generally, the objective of performing the panel co-integration diagnostics was to identify whether the series bear an asymptotic long-run relationship.

Basing on the findings, both trace and maximum statistics at none fail to accept the null hypothesis an intuition that there is co-integration at least 1 co-integration equations evident from the significance of the trace and maximum statistics: [26.5] and [20.9] respectively. On the same note, the $t$-statistics [-2.10] by Kao suggest failure to accept the null hypothesis of no long-run relationship in the panel. It is statistically significant with a point estimate of 0.02 (correct to two decimal place) at 5\% c.v. As a result, authors model a log-log based FMOLS and VECM models. Table 5 denotes these outputs. Table 6 on the other hand displays Wald outcomes from an unrestricted VAR (Vector Autoregressive) adopted to model the rectilinear interdependencies in the panel.

When, $\mathrm{CO}_{2}$ is the dependent variable, authors notice that $E u$ and $P g$ are statistically significant. An increase in energy use and population growth by $1 \%$ would cause an increase in $\mathrm{CO}_{2}$ concentration by $0.8 \%$ and $0.22 \%$ as confirmed by Refs. $[65,66]$. But on the other hand, economic output will be insignificant in contribution to environmental pollution. Similarly, a $1 \%$ sprawl in population growth decreases energy use by $2.96 \%$, an intuition that as population grows large the environmentalists suggest for the adoption and indeed implementation of energy saving and environment friendly sources. Authors also note that a $1 \%$ energy use scale up increases economic output by $0.09 \%$ as supported by Ref. [67] and reduces population growth by $0.13 \%$. On the other hand, a $1 \%$ expansion in output skyrockets energy use by $1.10 \%$. In addition, as $\mathrm{CO}_{2}$ concentration increases by $1 \%$, 
energy use and population growth increases by $2.82 \%$ and $0.36 \%$ respectively. These evidences support the results of Refs. [68, 69].

The chi-square statistics attest insignificance of the short-run causality among $\mathrm{CO}_{2}, \mathrm{Eu}, \mathrm{GDP}$ and $\mathrm{Pg}$. All the statistics tested for the short run are significantly close to zero. Consequently, authors fail to reject the null hypothesis of no short-run causality amongst the variables. In the end, a long-run relationship exists for economic output and energy use while population growth will be explosive. Both $G D P$ and $E u$ have their coefficients negative except for population growth and statistically significant at $1 \%$ and $10 \%$ c.v. Authors realize that due to a shock in the system both economic output, energy use and population sprawl will deviate. Finally, output and energy use will converge back to a steady state equilibrium at a rate of $0.002 \%$ and $0.002 \%$ respectively while population growth will be slightly explosive at $0.003 \%$.

The results in Table 7 authenticate invalidity of short-run causality amongst output, energy use and population growth except for environmental pollution. The invalid variables have insignificant $\chi^{2}$ statistic due to failure to reject the null hypothesis of no short-run causality as concurred by the ECT model in Table 5 for short run, which slightly opposes the regression of
$\mathrm{CO}_{2}$. Consequently, in Sub-Saharan African economies, economic output, energy use and population exist independent of each other. These outcomes coincide with short-run results due to VECM modelling except for $\mathrm{CO}_{2}$.

The residuals for the FMOLS models portray a normal distribution except for the model in the first column-first row with a significant test statistics of 18.667 at 5\% C.V. Similarly, when population growth modeled as the target variable using VECM model, its residuals suffer serial dependence across the panel, which might be a disadvantage. In the VAR column, the equations seem to fit the data appropriately due to statistically insignificant test statistics, an indication, and the estimated parameters by VAR are unbiased and best linear estimator.

Table 8 and Fig. 1 below depict the Impulse Response Functions plots and variance decomposition respectively.

$\mathrm{CO}_{2}$ as a proxy to environmental pollution and economic growth to own shocks responds positively for the first 3.5 years and 4 years respectively then flattens until the end of the forecast period. With energy use and population growth unto own shocks, response is positive followed by negative response for 2.5 and 3 years respectively. The series then flatten

Table 7 Block exogeniety Wald's test.

\begin{tabular}{lll}
\hline Models' & Chi square statistics & Probability $\left(\chi^{2}\right)$ \\
\hline Dependent variable & 1.819 & $0.061^{*}$ \\
$\mathrm{CO}_{2}$ & 2.513 & 0.479 \\
$\mathrm{Eu}$ & 1.620 & 0.654 \\
$\mathrm{Pg}$ & 2.540 & 0.468 \\
$\mathrm{GDP}$ & & \\
\hline
\end{tabular}

* denote rejection at $0.10 \%$ C.V Optimal lag is 1 to 1 , Model types used: log-log.

Table 8 Model diagnostics.

\begin{tabular}{llll}
\hline & FMOLS & VECM & VAR \\
\hline $\begin{array}{l}\text { Models' } \\
\text { Dependent variable }\end{array}$ & Normality test & Cross sectional dependence & $\begin{array}{l}\text { Portmanteau serial correlation } \\
\text { test }\end{array}$ \\
\hline $\mathrm{CO}_{2}$ & $18.669(0.00)^{* *}$ & $0.473(0.636)$ & $9.085(0.909)$ \\
$\mathrm{Eu}$ & $2.038(0.361)$ & $0.009(0.993)$ & $9.085(0.909)$ \\
$\mathrm{GDP}$ & $4.043(0.132)$ & $0.784(0.433)$ & $9.085(0.909)$ \\
$\mathrm{Pg}$ & $4.799(0.091)$ & $3.428(0.000)^{* *}$ & $9.085(0.909)$ \\
\hline
\end{tabular}

\footnotetext{
** denote rejection at $0.5 \%$ C.V , Model types used: $\log$-log.
} 


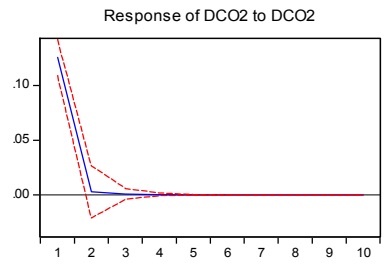

Response of DEU to DCO2

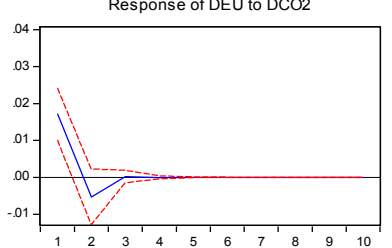

Response of DGDP to DCO2

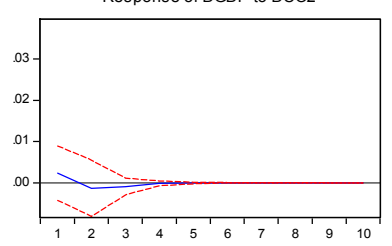

Response of DPG to DCO2

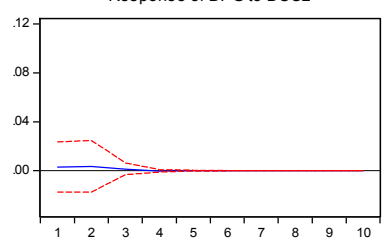

Response to Cholesky One S.D. (d.f. adjusted) Innov ations \pm 2 S.E.

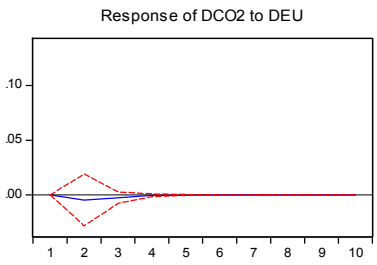

Response of DEU to DEU

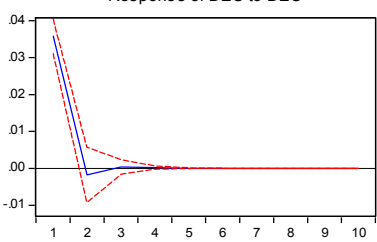

Response of DGDP to DEU

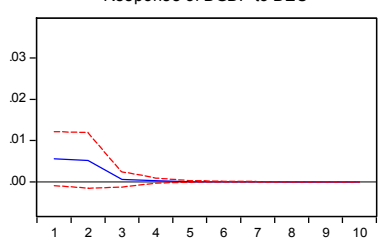

Response of DPG to DEU

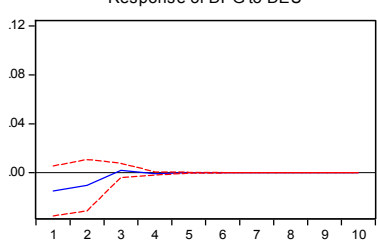

Response of DCO2 to DGDP

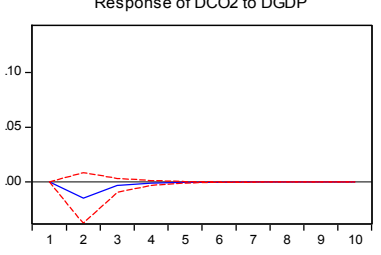

Response of DEU to DGDP

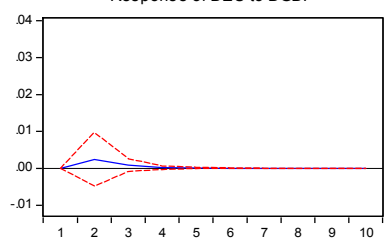

Response of DGDP to DGDP

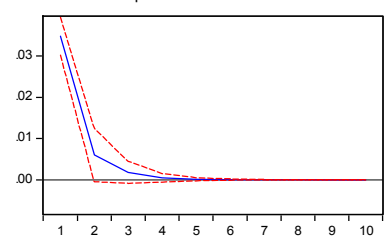

Response of DPG to DGDP

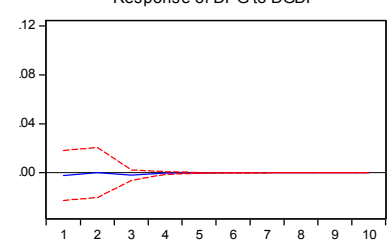

Response of DCO2 to DPG

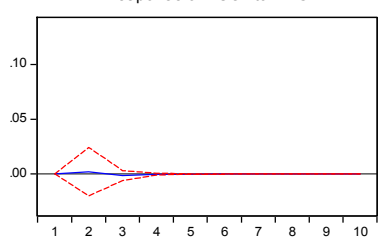

Response of DEU to DPG

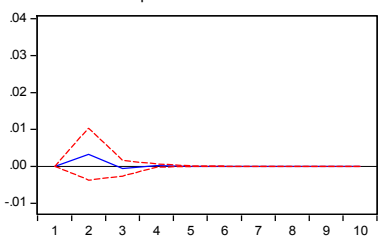

Response of DGDP to DPG

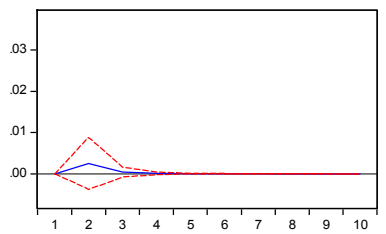

Response of DPG to DPG

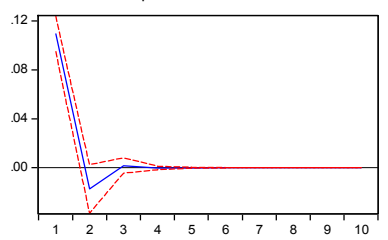

Fig. 1 Impulse response function.

until the end of the horizon. Elsewhere, the response of environmental pollution to energy use and economic growth, population growth to energy use and economic growth, traces from negative for the first 3 to 4 years then levels off for the rest of the forecast period. Other series responds generally positive then levels off when shocked up. For instance, environmental pollution to population sprawl, energy use to economic growth, and population sprawl, economic growth to energy use and population growth, population growth to environment pollution that responds generally positive and levels for the rest of the forecast period. Generally, when the variables experience an innovation by Cholesky one standard deviation, the response is either positive or negative for the first to 4 years in a bid to maintain stability.

The table below depicts the variance decomposition of the shocks in the variables. Their ordering is by

Cholesky: $\mathrm{CO}_{2}$, Eu, GDP, Pg.

Authors note that in the long run (by 2026), economic growth will be the most environment degrader at 1.39 units followed by energy use at 0.16 units and population growth at 0.04 units. Rather as time goes from the forecast period, environmental degradation increases gradually as depicted in Table 8 . The effect of environmental degradation, economic growth and population growth unto energy use increases gradually in the short run but as from 2022, the effect levels off at 19.72 units, 0.41 and 0.68 units respectively until the end of the forecast period. When economic growth is the target variable, the effects from environmental pollution, energy use and population growth increase gradually in the short run but level off at $0.61,4.38$ and 0.47 units respectively for the whole long-run cycle. On the other hand, when population growth is the dependent variable, effect from environmental 
Table 9 Variance decomposition.

\begin{tabular}{|c|c|c|c|c|c|}
\hline \multicolumn{6}{|c|}{$\mathrm{CO}_{2}$} \\
\hline Period & S.E. & $\mathrm{CO}_{2}$ & $\mathrm{Eu}$ & GDP & $\mathrm{Pg}$ \\
\hline 1 & 0.125891 & 100.0000 & 0.000000 & 0.000000 & 0.000000 \\
\hline 2 & 0.126864 & 98.52703 & 0.126058 & 1.320699 & 0.026211 \\
\hline 3 & 0.126939 & 98.41658 & 0.162341 & 1.381820 & 0.039254 \\
\hline 4 & 0.126944 & 98.41022 & 0.162958 & 1.387430 & 0.039397 \\
\hline 5 & 0.126945 & 98.40971 & 0.163080 & 1.387802 & 0.039413 \\
\hline 6 & 0.126945 & 98.40967 & 0.163086 & 1.387829 & 0.039415 \\
\hline 7 & 0.126945 & 98.40967 & 0.163087 & 1.387831 & 0.039415 \\
\hline 8 & 0.126945 & 98.40967 & 0.163087 & 1.387831 & 0.039415 \\
\hline 9 & 0.126945 & 98.40967 & 0.163087 & 1.387831 & 0.039415 \\
\hline 10 & 0.126945 & 98.40967 & 0.163087 & 1.387831 & 0.039415 \\
\hline \multicolumn{6}{|l|}{$\mathrm{Eu}$} \\
\hline Period & S.E. & $\mathrm{CO}_{2}$ & $\mathrm{Eu}$ & GDP & $\mathrm{Pg}$ \\
\hline 1 & 0.039743 & 18.56591 & 81.43409 & 0.000000 & 0.000000 \\
\hline 2 & 0.040336 & 19.73312 & 79.25292 & 0.358464 & 0.655498 \\
\hline 3 & 0.040351 & 19.72019 & 79.20135 & 0.403112 & 0.675349 \\
\hline 4 & 0.040352 & 19.71948 & 79.19922 & 0.404373 & 0.676921 \\
\hline 5 & 0.040352 & 19.71949 & 79.19903 & 0.404562 & 0.676920 \\
\hline 6 & 0.040352 & 19.71949 & 79.19902 & 0.404572 & 0.676920 \\
\hline 7 & 0.040352 & 19.71949 & 79.19902 & 0.404573 & 0.676920 \\
\hline 8 & 0.040352 & 19.71949 & 79.19902 & 0.404573 & 0.676920 \\
\hline 9 & 0.040352 & 19.71949 & 79.19902 & 0.404573 & 0.676920 \\
\hline 10 & 0.040352 & 19.71949 & 79.19902 & 0.404573 & 0.676920 \\
\hline \multicolumn{6}{|l|}{ GDP } \\
\hline Period & S.E. & $\mathrm{CO}_{2}$ & $\mathrm{Eu}$ & GDP & $\mathrm{Pg}$ \\
\hline 1 & 0.035391 & 0.427639 & 2.476536 & 97.09582 & 0.000000 \\
\hline 2 & 0.036376 & 0.547073 & 4.368173 & 94.62183 & 0.462928 \\
\hline 3 & 0.036439 & 0.608885 & 4.378668 & 94.53987 & 0.472573 \\
\hline 4 & 0.036444 & 0.610181 & 4.382716 & 94.53417 & 0.472937 \\
\hline 5 & 0.036444 & 0.610367 & 4.382941 & 94.53367 & 0.473020 \\
\hline 6 & 0.036444 & 0.610378 & 4.382955 & 94.53364 & 0.473023 \\
\hline 7 & 0.036444 & 0.610379 & 4.382956 & 94.53364 & 0.473023 \\
\hline 8 & 0.036444 & 0.610379 & 4.382956 & 94.53364 & 0.473023 \\
\hline 9 & 0.036444 & 0.610379 & 4.382956 & 94.53364 & 0.473023 \\
\hline 10 & 0.036444 & 0.610379 & 4.382956 & 94.53364 & 0.473023 \\
\hline \multicolumn{6}{|l|}{$\mathrm{PG}$} \\
\hline Period & S.E. & $\mathrm{CO}_{2}$ & $\mathrm{Eu}$ & GDP & $\mathrm{Pg}$ \\
\hline 1 & 0.110413 & 0.074165 & 1.823772 & 0.043472 & 98.05859 \\
\hline 2 & 0.112271 & 0.173714 & 2.576302 & 0.042087 & 97.20790 \\
\hline 3 & 0.112328 & 0.191567 & 2.599913 & 0.075616 & 97.13290 \\
\hline 4 & 0.112331 & 0.191885 & 2.602632 & 0.076067 & 97.12942 \\
\hline 5 & 0.112331 & 0.191951 & 2.602629 & 0.076134 & 97.12929 \\
\hline 6 & 0.112331 & 0.191951 & 2.602630 & 0.076140 & 97.12928 \\
\hline 7 & 0.112331 & 0.191951 & 2.602630 & 0.076140 & 97.12928 \\
\hline 8 & 0.112331 & 0.191951 & 2.602630 & 0.076140 & 97.12928 \\
\hline 9 & 0.112331 & 0.191951 & 2.602630 & 0.076140 & 97.12928 \\
\hline 10 & 0.112331 & 0.191951 & 2.602630 & 0.076140 & 97.12928 \\
\hline
\end{tabular}


pollution, energy use and population growth grows gradually but levels off at $0.19,2.60$ and 0.08 units respectively.

\section{Conclusion}

This research has theoretically endeavoured to examine the impact of economic growth, energy use, and population growth on environmental pollution for the five selected Sub-Saharan African nations: Kenya, Nigeria, Botswana, Benin and Mauritius selected for the period of 1990-2014. The study employed a complete conceptual framework including a unit root test, a co-integration test, panel VECM, and FMOLS econometric models. The panel VECM was used to identify the long-run causality and asymptotic convergence among the variables.

The empirical findings indicate that when the $\mathrm{CO}_{2}$ is the dependent variable, $\mathrm{Eu}$ and $\mathrm{Pg}$ are statistically significant. The findings show that projected coefficients of the lagged ECT in the energy use and population growth are statistically significant. This implies that these two variables are capable of playing a vital part in the modification procedure as the structure advances to the long-run equilibrium. Ref. [70] is also in agreement with authors' findings.

The empirical results account that the use of fossil fuels and solid fuel and the increase of population in Sub-Saharan Africa, significantly contribute to $\mathrm{CO}_{2}$ emissions. The use of these nonrenewable energies demands for a vigorous attention to mitigate $\mathrm{CO}_{2}$ emissions. Governments should invest into renewable energy systems to ensure sustainable economic enhancement in Sub-Saharan Africa. This will reduce the cumulative amount of $\mathrm{CO}_{2}$ emission per unit any given variable.

Basing on the findings, economic output negatively causes $\mathrm{CO}_{2}$. This indicates that letting the economy grow will increase the eminence of the environment. Economic growth should be improved through eco-innovation technologically. Governments should also encourage green energy technology. Since population growth form the leading emitter of carbon emissions among the selected Sub Saharan Africa, governments should encourage the introduction of e-transport for instance, the use of e-bikes, e-cars, e-train and e-buses like China and taxation of carbon emissions to control it in the future.

Governments should invest heavily in public transport to reduce on the purchasing of private cars by individuals to reduce on air pollution and traffic jam. Once governments control the transport sector by introducing e-transportation, it will help in the reduction of carbon emissions.

Since economic growth is not the leading producer of carbon emissions, more investment should be in renewable energy sources like hydro-electricity, nuclear power, thermal energy for economic development. To deal with carbon emission, carbon capturing and storage or sequestration should be highly considered to be a relevant technology as industries continue using fossil fuel to produce energy. This will help to avert the discharge of huge amount of carbon emissions into the space.

Governments should also initiate educational program about the dangers associated with carbon emission in Sub-Saharan Africa and the world at large. These educative programs will create awareness and the citizens will be cautious about the dangers of carbon emissions. Governments should also make sure that those responsible implement the recommended policies. Those who fail to comply should face the full force of the law for acting rebelliously. Governments should also invest a lot in research to help them to identify the effect of carbon emissions on the lives of their population. Governments should embrace climate change procedures into the states methodologies, strategies and design for bolstering of their nations to achieve sustainable development. In conclusion, all dependent variables in this study have different aggregates of impact on the environment in the selected emerging nations by setting up strong policies to enmesh carbon emissions mainly emitted 
by population and energy use.

\section{Author Contributions}

All authors equally participated in the preparation of this manuscript.

\section{Conflict of Interest}

The declaration by the authors is that there is no conflict of interest.

\section{Acknowledgements}

This work was supported in part by the National Science Foundation of China under grants 71471076, 71704066 and 71671080 and 71701090 and 71501084 . This work was also supported by the Special Funds of the National Social Science Fund of China [18VSJ038] and by Jiangsu Provincial Natural Science Foundation of China (Grant No. BK20170542).

\section{References}

[1] Sarkodie, S. A., and Adams, S. 2018. "Renewable Energy, Nuclear Energy and Environmental Pollution.

[2] Accounting Political Institutional Quality in South Africa. Science of The Total Environment 643: 1590-601.

[3] Apergis, N., Ben Jebli, M., and Ben Youssef, S. 2018. "Does Renewable Energy Consumption and Health Expenditures Decrease Carbon Dioxide Emissions? Evidence for Sub-Saharan Africa Countries." Renewable Energy.

[4] Razali, R., Khan, H., Shafie, A., and Hassan, A. R. 2016. "The Relationship between Energy Consumption and Economic Growth in Malaysia: ARDL Bound Test Approach.” AIP Conference Proceedings 1787: 080020.

[5] Ozturk, I. 2017. "The Dynamic Relationship between Agricultural Sustainability and Food-Energy-Water Poverty in a Panel of Selected Sub-Saharan African Countries." Energy Policy 107: 289-99.

[6] Hamilton, T. G. A., and Kelly, S. 2017. "Low Carbon Energy Scenarios for Sub-Saharan Africa: An Input-Output Analysis on the Effects of Universal Energy Access and Economic Growth." Energy Policy 105: 303-19.

[7] Asumadu-Sarkodie, S., and Owusu, P. A. 2016. "The Relationship between Carbon Dioxide and Agriculture in Ghana: A Comparison of VECM and ARDL Model." Environmental Science and Pollution Research 23 (11): 10968-82.
[8] Sirag, A., Mohamed Nor, N., Law, S. H., Abdullah, N. M. R., and Lacheheb, M. 2017. "The Impact of Health Financing and $\mathrm{CO}_{2}$ Emission on Health Outcomes in Sub-Saharan Africa: A Cross-Country Analysis." Geo. Journal 82 (6): 1247-61.

[9] de Vries, G. J., and Ferrarini, B. 2017. "What Accounts for the Growth of Carbon Dioxide Emissions in Advanced and Emerging Economies? The Role of Consumption, Technology and Global Supply Chain Participation." Ecological Economics 132: 213-23.

[10] Kahiu, M. N., and Hanan, N. 2018. "Fire in Sub-Saharan Africa: The Fuel, Cure and Connectivity Hypothesis." Global Ecology and Biogeography.

[11] Brandt, M., Rasmussen, K., Peñuelas, J., Tian, F., Schurgers, G., Verger, A., et al. 2017. "Human Population Growth Offsets Climate-Driven Increase in Woody Vegetation in Sub-Saharan Africa." Nature Ecology \& Evolution 1 (4): 0081.

[12] Hanif, I. 2018. "Impact of Economic Growth, Nonrenewable and Renewable Energy Consumption, and Urbanization on Carbon Emissions in Sub-Saharan Africa." Environmental Science and Pollution Research.

[13] Hanif, I. 2018. "Energy Consumption Habits and Human Health Nexus in Sub-Saharan Africa." Environmental Science and Pollution Research.

[14] Climate \& Clean Air Coalition. 2018. "World Health Organization Releases New Global Air Pollution Data." CLIMATE \& CLEAN AIR COALITION. Accessed July 28, 2018. http://www.ccacoalition.org/en/news/world-health-organi zation-releases-new-global-air-pollution-data.

[15] Lelieveld, J., Evans, J., Fnais, M., Giannadaki, D., and Pozzer, A. 2015. "The Contribution of Outdoor Air Pollution Sources to Premature Mortality on a Global Scale." Nature 525 (7569): 367-71.

[16] Tilman, D., Clark, M., Williams, D. R., Kimmel, K., Polasky, S., and Packer, C. 2017. "Future Threats to Biodiversity and Pathways to Their Prevention." Nature 546 (7656): 73.

[17] Corbeels, M., Cardinael, R., Naudin, K., Guibert, H., and Torquebiau, E. 2018. "The 4 per 1000 Goal and Soil Carbon Storage under Agroforestry and Conservation Agriculture Systems in Sub-Saharan Africa." Soil and Tillage Research.

[18] Cumming, T. L., Shackleton, R. T., Förster, J., Dini, J., Khan, A., Gumula, M., et al. 2017. "Achieving the National Development Agenda and the Sustainable Development Goals (SDGs) through Investment in Ecological Infrastructure: A Case Study of South Africa." Ecosystem Services 27: 253-60.

[19] Paustian-Underdahl, S. C., Fainshmidt, S., Sanchez, J. I., 
Misati, E., Zhao, Y., and Zhang, H. 2017. "The Role of Economic Development and Perceived Growth Opportunities in Employee Reactions to M\&As: A Study of the Merger Syndrome across 29 Countries." Group \& Organization Management 42 (2): 163-94.

[20] Jeanjean, A. P. R., Gallagher, J., Monks, P. S., and Leigh, R. J. 2017. "Ranking Current and Prospective $\mathrm{NO}_{2}$ Pollution Mitigation Strategies: An Environmental and Economic Modelling Investigation in Oxford Street, London." Environmental Pollution 225: 587-97.

[21] Aye, G. C., and Edoja, P. E. 2017. "Effect of Economic Growth on $\mathrm{CO} 2$ Emission in Developing Countries: Evidence from a Dynamic Panel Threshold Model." Cogent Economics \& Finance 5 (1).

[22] Antonakakis, N., Chatziantoniou, I., and Filis, G. 2017. "Energy Consumption, $\mathrm{CO}_{2}$ Emissions and Economic Growth: An Ethical Dilemma." Renewable and Sustainable Energy Reviews 68: 808-24.

[23] Kivyiro, P., and Arminen, H. 2014. "Carbon Dioxide Emissions, Energy Consumption, Economic Growth and Foreign Direct Investment: Causality Analysis for Sub-Saharan Africa." Energy 74: 595-606.

[24] Al-Mulali, U., Ozturk, I., and Lean, H. H. 2015. "The Influence of Economic Growth, Urbanization, Trade Openness, Financial Development, and Renewable Energy on Pollution in Europe." Natural Hazards 79 (1): 621-44.

[25] Mendum, R., and Njenga, M. 2018. "Integrating Wood Fuels into Agriculture and Food Security Agendas and Research in Sub-Saharan Africa." FACETS 3 (1): $1-11$.

[26] Shahsavari, A., and Akbari, M. 2018. "Potential of Solar Energy in Developing Countries for Reducing Energy-Related Emissions.” Renewable and Sustainable Energy Reviews 90: 275-91.

[27] Zaman, K., Ahmad, A., Hamzah, T. A. A. T., and Yusoff, M. M. 2016. "Environmental Factors Affecting Health Indicators in Sub-Saharan African Countries: Health Is Wealth.” Social Indicators Research 129 (1): 215-28.

[28] Jamel, L., Derbali, A., and Charfeddine, L. 2016. "Do Energy Consumption and Economic Growth Lead to Environmental Degradation? Evidence from Asian Economies." Cogent Economics \& Finance 4 (1).

[29] Obradović, S., and Lojanica, N. 2017. "Energy Use, $\mathrm{CO}_{2}$ Emissions and Economic Growth-Causality on a Sample of SEE Countries." Economic Research-Ekonomska Istraživanja 30 (1): 511-26.

[30] Boamah, K. B., Du, J., Bediako, I. A., Boamah, A. J., Abdul-Rasheed, A. A., and Owusu, S. M. 2017. "Carbon Dioxide Emission and Economic Growth of China-The Role of International Trade." Environmental Science and
Pollution Research 24 (14): 13049-67.

[31] Acaravci, A., and Ozturk, I. 2010. "On the Relationship between Energy Consumption, $\mathrm{CO}_{2}$ Emissions and Economic Growth in Europe.” Energy 35 (12): 5412-20.

[32] Jayanthakumaran, K., Verma, R., and Liu, Y. 2012. " $\mathrm{CO}_{2}$ Emissions, Energy Consumption, Trade and Income: A Comparative Analysis of China and India." Energy Policy 42: 450-60.

[33] Wolde-Rufael, Y. 2009. "Energy consumption and economic growth: The experience of African countries revisited." Energy Economics 31 (2): 217-24.

[34] Wolde-Rufael, Y. 2006. "Electricity Consumption and Economic Growth: A Time Series Experience for 17 African Countries." Energy Policy 34 (10): 1106-14.

[35] Ozturk, I., Aslan, A., and Kalyoncu, H. 2010. "Energy Consumption and Economic Growth Relationship: Evidence from Panel Data for Low and Middle Income Countries." Energy Policy 38 (8): 4422-8.

[36] Ozturk, I., and Bilgili, F. 2015. "Economic Growth and Biomass Consumption Nexus: Dynamic Panel Analysis for Sub-Sahara African Countries." Applied Energy 137: 110-6.

[37] Salahuddin, M., Gow, J., and Ozturk, I. 2015. "Is the Long-Run Relationship between Economic Growth, Electricity Consumption, Carbon Dioxide Emissions and Financial Development in Gulf Cooperation Council Countries Robust?" Renewable and Sustainable Energy Reviews 51: 317-26.

[38] Karanfil, F., and Li, Y. 2015. "Electricity Consumption and Economic Growth: Exploring Panel-Specific Differences." Energy Policy 82: 264-77.

[39] Zerbo, E. 2017. "Energy Consumption and Economic Growth in Sub-Saharan African Countries." Economics Bulletin 37 (3): 1720-44.

[40] Yasar, N. 2017. "The Relationship between Energy Consumption and Economic Growth: Evidence from Different Income Country Groups.” International Journal of Energy Economics and Policy 7 (2).

[41] Payne, J. E. 2010. "A Survey of the Electricity Consumption-Growth Literature." Applied Energy 87 (3): 723-31.

[42] Kalimeris, P., Richardson, C., and Bithas, K. 2014. "A Meta-Analysis Investigation of the Direction of the Energy-GDP Causal Relationship: Implications for the Growth-Degrowth Dialogue." Journal of Cleaner Production 67: 1-13.

[43] Ahmed, M., and Azam, M. 2016. "Causal Nexus between Energy Consumption and Economic Growth for High, Middle and Low Income Countries Using Frequency Domain Analysis." Renewable and Sustainable Energy Reviews 60: 653-78.

[44] Arouri, M. E. H., Ben Youssef, A., M'Henni, H., and 
Rault, C. 2012. "Energy Consumption, Economic growth and $\mathrm{CO} 2$ Emissions in Middle East and North African Countries." Energy Policy 45: 342-9.

[45] Ang, J. B. 2007. " $\mathrm{CO}_{2}$ Emissions, Energy Consumption, and Output in France.” Energy Policy 35 (10): 4772-8.

[46] Elliott, R. J. R., Sun, P., and Zhu, T. 2017. "The Direct and Indirect Effect of Urbanization on Energy Intensity: A Province-Level Study for China." Energy 123: 677-92.

[47] Zhang, Y.-J., and Da, Y.-B. 2015. "The Decomposition of Energy-Related Carbon Emission and Its Decoupling with Economic Growth in China." Renewable and Sustainable Energy Reviews 41: 1255-66.

[48] Begum, R. A., Sohag, K., Abdullah, S. M. S., and Jaafar, M. 2015. " $\mathrm{CO}_{2}$ Emissions, Energy Consumption, Economic and Population Growth in Malaysia." Renewable and Sustainable Energy Reviews 41: 594-601.

[49] Al-Mulali, U., and Ozturk, I. 2016. "The Investigation of Environmental Kuznets Curve Hypothesis in the Advanced Economies: The Role of Energy Prices." Renewable and Sustainable Energy Reviews 54: 1622-31.

[50] Appiah, K., Du, J., Musah, A.-A., and Afriyie, S. 2017. "Investigation of the Relationship between Economic Growth and Carbon Dioxide $\left(\mathrm{CO}_{2}\right)$ Emissions as Economic Structure Changes: Evidence from Ghana." Resources and Environment 7 (6): 160-7.

[51] Inglesi-Lotz, R., and Dogan, E. 2018. "The Role of Renewable Versus Non-renewable Energy to the Level of $\mathrm{CO}_{2}$ Emissions a Panel Analysis of Sub-Saharan Africa's Big 10 Electricity Generators." Renewable Energy 123: $36-43$.

[52] Lutz, W., O’Neill, F., and MacKellar, L. 2001. Population and Climate Change. International Institute for Applied Systems Analysis (IIASA) Cambridge University Press, Cambridge.

[53] Özokcu, S., and Özdemir, Ö. 2017. "Economic Growth, Energy, and Environmental Kuznets Curve." Renewable and Sustainable Energy Reviews 72: 639-47.

[54] Fan, Y., Liu, L.-C., Wu, G., and Wei, Y.-M. 2006. "Analyzing Impact Factors of $\mathrm{CO}_{2}$ Emissions Using the STIRPAT Model." Environmental Impact Assessment Review 26 (4): 377-95.

[55] Feng, K., Davis, S. J., Sun, L., and Hubacek, K. 2015. "Drivers of the US $\mathrm{CO}_{2}$ Emissions 1997-2013." Nature Communications 6: 7714

[56] Liddle, B., and Lung, S. 2010. "Age-Structure, Urbanization, and Climate Change in Developed Countries: Revisiting STIRPAT for Disaggregated Population and Consumption-Related Environmental Impacts." Population and Environment 31 (5): 317-43.

[57] Poumanyvong, P., and Kaneko, S. 2010. "Does
Urbanization Lead to Less Energy Use and Lower $\mathrm{CO}_{2}$ Emissions? A Cross-Country Analysis." Ecological Economics 70 (2): 434-44.

[58] Pedroni, P. 1999. "Critical Values for Cointegration Tests in Heterogeneous Panels with Multiple Regressors." Oxford Bulletin of Economics and Statistics 61 (S1): 653-70.

[59] Pedroni, P. 2004. "Panel Cointegration: Asymptotic and Finite Sample Properties of Pooled Time Series Tests with an Application to the PPP Hypothesis." Econometric Theory 20 (3): 597-625.

[60] Kao, C., and Chiang, M.-H. 2001. "On the Estimation and Inference of a Cointegrated Regression in Panel Data." In Nonstationary Panels, Panel Cointegration and Dynamic Panels. Emerald Group Publishing Limited, pp. 179-222.

[61] Engle, R. F., and Granger, C. W. 1987. "Co-integration and Error Correction: Representation, Estimation, and Testing. Econometrica." Journal of the Econometric Society 251-76.

[62] Hansen, B. E. 1992. "Testing for Parameter Instability in Linear Models." Journal of Policy Modeling 14 (4): 517-33.

[63] Phillips, P. C., and Hansen, B. E. 1990. "Statistical Inference in Instrumental Variables Regression with I (1) Processes." The Review of Economic Studies 57 (1): 99-125.

[64] Granger, C. W. J. 1988. "Causality, Cointegration, and Control." Journal of Economic Dynamics and Control 12 (2): 551-9.

[65] Johansen, S. 1991. "Estimation and Hypothesis Testing of Cointegration Vectors in Gaussian Vector Autoregressive Models. Econometrica." Journal of the Econometric Society 1551-80.

[66] Casey, G., and Galor, O. 2017. "Is Faster Economic Growth Compatible with Reductions in Carbon Emissions? The Role of Diminished Population Growth.” Environmental Research Letters 12 (1): 014003.

[67] Van der Zwaan, B., Kobe, T., Longa, F. D., van der Laan, A., and Jan Kramer, G. 2018. "An Integrated Assessment of Pathways for Low-Carbon Development in Africa." Energy Policy 117: 387-95.

[68] Ito, K. 2017. " $\mathrm{CO}_{2}$ Emissions, Renewable and Non-renewable Energy Consumption, and Economic Growth: Evidence from Panel Data for Developing Countries." International Economics 151: 1-6.

[69] Esso, L. J., and Keho, Y. 2016. "Energy Consumption, Economic Growth and Carbon Emissions: Cointegration and Causality Evidence from Selected African Countries." Energy 114: 492-7.

[70] Destek, M. A., and Aslan, A. 2017. "Renewable and Non-renewable Energy Consumption and Economic 
Growth in Emerging Economies: Evidence from Bootstrap Panel Causality." Renewable Energy 111: 757-63.

[71] Kasman, A., and Duman, Y. S. 2015. " $\mathrm{CO}_{2}$ Emissions,
Economic Growth, Energy Consumption, Trade and Urbanization in New EU Member and Candidate Countries: A Panel Data Analysis." Economic Modelling 44: 97-103. 